\title{
Central sensitization: a biopsychosocial explanation for chronic widespread pain in patients with fibromyalgia and chronic fatigue syndrome
}

\author{
Mira Meeus • Jo Nijs
}

Received: 20 June 2006 /Revised: 28 August 2006 / Accepted: 31 August 2006 / Published online: 18 November 2006

(C) Clinical Rheumatology 2006

\begin{abstract}
In addition to the debilitating fatigue, the majority of patients with chronic fatigue syndrome (CFS) experience chronic widespread pain. These pain complaints show the greatest overlap between CFS and fibromyalgia (FM). Although the literature provides evidence for central sensitization as cause for the musculoskeletal pain in FM, in CFS this evidence is currently lacking, despite the observed similarities in both diseases. The knowledge concerning the physiological mechanism of central sensitization, the pathophysiology and the pain processing in FM, and the knowledge on the pathophysiology of CFS lead to the hypothesis that central sensitization is also responsible for the sustaining pain complaints in CFS. This hypothesis is based on the hyperalgesia and allodynia reported in CFS,
\end{abstract}

Mira Meeus is financially supported by a Ph.D. grant ("Chronic pain in chronic fatigue syndrome: a biopsychosocial approach") supplied by the Higher Institute of Physiotherapy, Department of Health Sciences, Hogeschool Antwerpen, Antwerp, Belgium and co-financed by Faculty of Physical Education and Physiotherapy, Vrije Universiteit Brussel (VUB), Brussels, Belgium (OZR project OZ.R. 1234/MFYS Wer2).

M. Meeus $\cdot$ J. Nijs

Department of Human Physiology,

Faculty of Physical Education and Physiotherapy,

Vrije Universiteit Brussel (VUB),

Brussel, Belgium

M. Meeus $\cdot$ J. Nijs

Division of Musculoskeletal Physiotherapy,

Department of Health Sciences, University College Antwerp,

Antwerp, Belgium

J. Nijs $(\bowtie)$

Department of Health Sciences,

Division of Musculoskeletal Physiotherapy,

Hogeschool Antwerpen (HA),

Van Aertselaerstraat 31,

2170 Merksem, Belgium

e-mail: jo.nijs@vub.ac.be on the elevated concentrations of nitric oxide presented in the blood of CFS patients, on the typical personality styles seen in CFS and on the brain abnormalities shown on brain images. To examine the present hypothesis more research is required. Further investigations could use similar protocols to those already used in studies on pain in FM like, for example, studies on temporal summation, spatial summation, the role of psychosocial aspects in chronic pain, etc.

Keywords Central sensitization .

Chronic fatigue syndrome $\cdot$ Chronic pain $\cdot$ Fibromyalgia

\section{Introduction}

Chronic fatigue syndrome (CFS), as defined by the Centers for Disease Control and Prevention (CDCP), is a complex illness characterized by prolonged debilitating fatigue and multiple non-specific symptoms including headaches, recurrent sore throats, fever, muscle and joint pain, and neurocognitive complaints $[1,2]$. In addition to the chronic fatigue, widespread and persistent pain is common in individuals with CFS [3-5]. A population-based study revealed that $94 \%$ of the persons diagnosed with CFS report muscle aches and pain and 84\% report joint pain [6]. Nishikai et al. [7] reported muscle pain in 85 CFS patients of 114 patients (74.6\%). Seventy-four patients (64.9\%) complained of arthralgia. In another study, 24 of 44 patients suffered from chronic widespread pain [8]. Chronic fatigue accompanied by chronic musculoskeletal impairments such as myalgias and arthralgias could be considered an important subclass of CFS [9]. Evidence supportive of the clinical importance of widespread pain in CFS has been provided [10]: chronic pain accounts for up to $34 \%$ of the CFS patients' self-reported activity limitations and partic- 
ipation restrictions. Chronic pain is more disabling than chronic fatigue [10].

Given these facts, it may be surprising that the etiology of these pain complaints has not been studied extensively in patients with CFS. The systematic literature review by Meeus et al. [11] shows that only little progress has been made in understanding chronic widespread pain in patients with CFS. A few hypotheses have been proposed, but they have not been studied in depth or relatively little work has been performed to test these hypotheses. In contrast, a large body of scientific literature regarding the etiology of chronic pain complaints in fibromyalgia (FM) is currently available. The diagnosis of FM is based on the 1990 American College of Rheumatology criteria. Following these criteria, FM patients present with 11 of 18 positive tender points and with widespread pain [12]. Validity of both the definition for CFS and FM has been shown $[12,13]$.

Especially, investigations focusing on the phenomenon "central sensitization" are presented in force in FM. In CFS, the theory of central sensitization has only been suggested, to our knowledge [14]. Given the great overlap between CFS and FM [15] and given the dearth of studies focusing on the explanation for the chronic widespread pain in patients with CFS, it would be interesting to propose a theoretical model for the chronic pain in CFS based on the current knowledge of CFS and on the evidence for central sensitization in FM, giving rise to further research on that matter. Besides the knowledge on chronic pain in FM, it is necessary to gather knowledge on musculoskeletal pain in CFS.

The syndromes may overlap, but despite the similarities between the two syndromes, there are also differences. For example, immunological dysregulations such as the abnormal 2-5A synthetase/RNase L pathway [16] have been revealed in CFS but have never been detected in FM patients. Furthermore, there is not yet any good evidence for similar pain mechanisms in CFS and FM. Some authors already found evidence suggesting differences in pain processing. For example, patterns of functional brain activity in patients with FM are quite different from those in patients with CFS.

Patients with CFS, relative to controls, showed significantly lower blood perfusion in the brain stem [17, 18]. Patients with FM exhibited significantly lower rCBF levels, during rest, in the thalamus and the caudate nucleus [19]. Furthermore, Substance P has been found to be elevated in CSF of FM patients [20] and not in patients with CFS [21]. Therefore, the knowledge on pain in FM cannot be applied on CFS patients without further study. Based on the similarities and differences between the two syndromes, further research on pain in CFS is advised to get an image of pain processing in the two diseases.
The goal of this article is to provide a rational basis for future investigations. First, the concept of central sensitisation as a cause of chronic pain will be explained. This theoretical background will then be applied to FM and an overview of the evidence for central sensitization in FM will follow. Finally, based on the theoretical background and the findings in FM, the hypothesis concerning central sensitization in CFS will be unfolded, supported with the present knowledge on CFS.

\section{Central sensitization}

Introduction Pain is a complex perception that is influenced by prior experience and by the context within which the noxious stimulus occurs; "nociception" is the physiologic response to tissue damage or prior tissue damage [22]. The definition of pain is endorsed by the International Association for the Study of Pain: "Pain is an unpleasant sensory and emotional experience associated with actual or potential tissue damage, or described in terms of such damage" [23]. There are a host of physiologic mechanisms by which injuries lead to nociceptive responses and ultimately to pain [22]. However, not all nociceptive signals are perceived as pain and vice versa, not every pain sensation originates from nociception. Nevertheless, acute pain almost always originates from nociceptors in somatic or visceral tissue. Mainly two types of pain receptors are activated by nociceptive input. These include low-threshold nociceptors that are connected to fast conducting A-delta pain fibers, and high-threshold nociceptors that conduct impulses in slow (unmyelinated) $\mathrm{C}$ fibers. Within the dorsal horn of the spinal cord, these pain fibers synapse with spinal neurons via synaptic transmission. Many neurotransmitters (i.e., glutamate, substance $P$, etc.) are able to modulate the postsynaptic responses with further transmission to supraspinal sites (thalamus, anterior cingulated cortex, insular cortex, and somatosensory cortex) via the ascending pathways $[22,24,25]$.

The simplest form of plasticity in nervous systems is that repeated noxious stimulation may lead to habituation (decreased response) or sensitization (increased response) [26]. Prolonged or strong activity of dorsal horn neurons caused by repeated or sustained noxious stimulation may subsequently lead to increased neuronal responsiveness or central sensitization $[25,27]$. Neuroplasticity and subsequent CNS sensitization include altered function of chemical, electrophysiological, and pharmacological systems $[22,28,29]$. These changes cause exaggerated perception of painful stimuli (hyperalgesia), a perception of innocuous stimuli as painful (allodynia) and may be involved in the generation of referred pain and hyperalgesia across multiple spinal segments [25, 30-33]. 
While the exact mechanism by which the spinal cord becomes sensitized or in "hyperexcitable" state currently remains somewhat unknown, some contributing factors have been proposed.

Temporal summation or wind-up "Wind up" refers to a central spinal mechanism in which repetitive noxious stimulation results in a slow temporal summation that is experienced in humans as increased pain [34]. In 1965, animal experiments showed for the first time that repetitive $\mathrm{C}$-fiber stimulation could result in a progressive increase of electrical discharges from the second-order neuron in the spinal cord [35]. This mechanism of pain amplification in the spinal cord is related to temporal summation of second pain or wind-up. Second pain, which is more dull and strongly related to chronic pain states, is transmitted through unmyelinated $\mathrm{C}$ fibers to dorsal horn nociceptive neurons. During the $\mathrm{C}$-fibres transmitted stimuli, $\mathrm{N}$-methylD-aspartate (NMDA) receptors of second-order neurons become activated.

It is well-known that NMDA activation induces calcium entry into the dorsal horn neurons [36]. Calcium entry into sensory neurons in the dorsal horn induces activation of nitric oxide (NO) synthase, leading to the synthesis of NO [37]. NO can affect the nociceptor terminals and enhance the release of sensory neuropeptides (in particular, substance P) from presynaptic neurons, therefore contributing to the development of hyperalgesia and maintenance of central sensitization [38]. Substance P (SP) is an important nociceptive neurotransmitter. It lowers the threshold of synaptic excitability, resulting in the unmasking of normally silent interspinal synapses and the sensitization of second-order spinal neurons [39].

Furthermore, SP can extend for long distances in the spinal cord and sensitize dorsal horn neurons at a distance from the initial input locus. This results in an expansion of receptive fields and the activation of wide dynamic neurons by non-nociceptive afferent impulses [24].

Wind-up can be elicited in human patients if identical nociceptive stimuli are applied to the skin or muscles more often than once every $3 \mathrm{~s}$. The resulting progressive increase of pain sensations represents wind-up and has been demonstrated to result from a central rather than a peripheral nervous system mechanism, because the input from $\mathrm{C}$ nociceptors has been shown to decline or stay the same with stimulus repetition [40].

Endogenous pain modulatory systems The presence of several pain inhibitory and facilitatory centers in the brainstem is well recognized. The dorsolateral funiculus appears to be a preferred pathway for descending pain inhibitory systems [41]. Experimental evidence for the existence of descending inhibitory pathways, and their connection with central sensitization, include the observations that bilateral lesions of the dorsolateral funiculus in the rat led to a significant decrease in latency for paw withdrawal to noxious stimulus [42]. Similarly, temporary spinal cord block (lidocaine) caused dorsal horn nociceptive neurons to expand their receptive fields and their responsiveness to afferent input [43]. In addition, selective chemical lesion of serotonergic inhibitory neurons in experimentally "inflamed" animals resulted in demonstrable behavioral "pain" hypersensitivity [42].

The foregoing investigations suggest that disruption of one or more of the elements of the inhibitory system can result in, among other things, the equivalent of central sensitization [44]. One function of the descending inhibitory pathway is to "focus" the excitation of the dorsal horn neurons. The effect is to generate a more urgent, localized, and rapid pain signal by suppressing surrounding neuronal activity [45]. This role is attributed to the "diffuse noxious inhibitory controls" (DNIC) phenomenon [46]. According to this model, descending pathways effectively enhance the biologically valuable pain signal by reducing the level of irrelevant "noise" in the system.

Facilitatory pathways leading from the brainstem have also been identified. There is now behavioral evidence that forebrain centers are capable of exerting powerful clinically significant influences on various nuclei of the brainstem, including the nuclei identified as the origin of the descending facilitatory pathway [44]. The activity in descending pathways is not constant but can be modulated, for example, by the level of vigilance or attention and by stress [47]. Brosschot [48] refers to it as cognitive emotional sensitization. Forebrain products such as cognitions, emotions, attention, and motivation have influence on the clinical pain experience [44].

Dubner and Ren [41] rewarded subjects for responding to a randomly delivered transient tissue threatening peripheral stimulus. It was found that sensitization of secondorder pain pathway neurons was directly related to the strength of attention. The evidence suggests that selective attention to relevant stimuli activated descending pain modulatory systems, turning the balance in favor of facilitation. The dominance of descending facilitation then led to sensitization of second-order neurons [44]. Behavioral variables such as attention to a potentially threatening stimulus result in sensitization of dorsal horns spinal cord neurons. Moreover, behavioral modulation associated with selective attention to a perceived threat utilizes the same forebrain and brainstem structures and mechanisms as are involved in the development, amplification, and maintenance of persistent pain after actual tissue damage and inflammation [41].

Certain cognitive styles and personality traits have been associated with amplification of pain and its extension in 
the absence of tissue damage. These include somatization, catastrophizing, and hypervigilance [49-52]. Thus, via descending pathways behavioral and cognitive therapies might also effect synaptic transmission in the spinal cord and thereby have the capacity to prevent or reverse longterm changes of synaptic strength in pain pathways [47].

\section{Evidence in FM}

Exaggerated pain is common in whiplash and FM patients. Theoretically, peripheral mechanisms can account for the pain hypersensitivity. In FM, however, there is no evidence for peripheral sensitization as the cause of hyperalgesia, given the absence of real tissue damage. Peripheral sensitization is defined as a reduction in the threshold of nociceptive afferent receptors caused by a local change in the sensitivity of sensory fibers initiated by tissue damage [53]. Peripheral sensitization almost always depends on local inflammation, which may lead to decreased nociceptor thresholds. Despite extensive investigations, no tissue pathology, structural abnormalities, or evidence for a source of chronic stimulation of pain afferents have been detected in fibromyalgic patients [54].

Furthermore, FM pain lacks a distinct spatial localization [55]. This suggests that pathophysiological central mechanisms contribute to or are responsible for FM pain [56]. This has led to the hypothesis that the central nervous system is hyperexcitable in these patients. Central hypersensitivity could explain exaggerated pain in the presence of minimal and undetectable tissue damage, in that the nociceptive signal is amplified by the hyperexcitable neurons [57].

Pain measurements Studies in patients with chronic pain after whiplash injury and with FM have demonstrated exaggerated pain responses after sensory stimulation of healthy tissues [55, 58-63]. For example, at same level of thermal stimulation, FM patients perceived pain as 49 and $52 \%$ more intense than healthy controls and patients with low-back pain [61]. After-sensations at $15 \mathrm{~s}$ after heat taps were regarded as painful on $83 \%$ of FM patients, compared to $37 \%$ pain reports of healthy controls. The late aftersensations ( $2 \mathrm{~min}$ after heat stimulation) were rated as painful in 55 and $5 \%$ of $\mathrm{FM}$ and control subjects, respectively [55]. It was not mentioned in the results if all FM patients were subject to increased sensitivity, but there were always significant differences between the FM patients and the healthy controls.

Although most comparisons were made to pain-free subjects, some researchers, like Julien et al. [61], even compared the pain responses of FM patients to other pain patients, such as patients with chronic low-back pain. They could also report significant differences. Despite the lack of research into the contribution of psychological factors in wind-up, these results suggest that input to central nociceptive pathways is abnormally processed in patients with FM. Intramuscular electrical stimulation has been used to assess the efficacy of temporal summation of painful muscle stimuli. Temporal stimulation was found to be more pronounced and to cause stronger pain and larger referred areas in FM patients compared to controls [60].

The increased efficacy of temporal summation in FM has even so been reproduced with cutaneous heat stimulation [55] and with cold and heat taps [59]. Facilitated temporal summation in patients with pain suggests that the efficacy of central processing is increased (central sensitization) in these patients [64]. In addition, after-sensation was greater in magnitude, lasted longer, and was more frequently painful in patients with FM [55]. The prolonged decay together with the augmentation provides evidence for the presence of central sensitization [24, 25]. Immersion of the arm in circulating noxious cold water resulted in a $49 \%$ more intense pain in FM patients compared to healthy controls [61]. Further evidence of central sensitization in FM is seen by enlarged referred pain areas. Sörensen et al. [60] found that fibromyalgic patients experienced stronger pain and larger referred areas after intramuscular injection of hypertonic saline.

Moreover, spatial summation effect during increase of the stimulation area was found only in patients with FM and not in healthy controls or in patients with chronic lowback pain [61]. This indicates that pain inhibitory systems are not optimally recruited in patients with FM. FM patients perceived pain at the same intensities and unpleasantness during the ascending and the descending sessions (fingertip to shoulder and shoulder to fingertip immersion). In healthy controls and patients with low-back pain, the noxious stimulation of a large surface area results in an activation of a large population of nociceptive afferents that induce endogenous inhibitory responses, resulting in a decreased response in the dorsal horn neurons, and subsequently leads to lower pain intensities afterward.

Given that FM patients experience similar pain intensities in the descending session after noxious stimulation of the whole arm, this study clearly demonstrated that FM patients present with a lack of activation of endogenous inhibitory systems [61]. Secondly, Lautenbacher and Rollman [65] showed that tonic painful and non-painful thermal stimulation of the foot increased the pain thresholds to electrical stimulation applied to a non-tender point (inner forearm) in healthy controls but had no effect on patients with FM. Kosek and Hansson [66] found that tourniquet ischemic pain in an arm increased the pressure pain threshold in healthy controls but not in FM patients, 
suggesting once more a deficiency in the latter of a paininhibitory phenomenon termed "diffuse noxious inhibitory control" (DNIC) [66, 67]. Similarly, aerobic exercise has been shown to decrease wind-up pain in normal subjects but increased it in FM patients, suggesting the possibility of reduced endogenous analgesic mechanisms [68]. Also, isometric exercise (i.e., hand-grip exercise) resulted in increased thermal pain ratings and decreased pain thresholds, both ipsilateral and contralateral to the exercised extremity [69]. These investigations support a general hypothesis that FM reflects a disorder affecting modulation of pain sensitivity $[66,67]$. In one such scenario, tonic DNIC is present in the normal situation, and its pathological absence results in the spontaneous pain and evoked pain sensitivity associated with FM [34].

Measurements of excitability The results of the abovementioned studies, however, are based on pain reports of the patients and thus subjective in nature, and it was not clear whether this hypersensitivity was the result of central mechanisms or whether the hypersensitivity was the cause of hypervigilance. Banic et al. [57] could provide objective evidence by quantifying the minimal intensity of transcutaneous electrical stimulation of the sural nerve required to evoke flexion reflex in the biceps femoris. This study clearly demonstrates that spinal cord neurons are sensitized in chronic pain after whiplash and in patients with FM; because the stimuli were delivered at random time intervals and the latency of EMG response was measured, voluntary symptom amplification could be ruled out. Moreover, the electrical stimulation bypasses peripheral receptors.

Cognitive emotional sensitization Patients with FM or other pain disorders often receive the message that it is "all in their head". One construct that has been hypothesized to explain the pain amplification in FM is that of hypervigilance [34]. This hypothesis of hypervigilance has been argued by McDermid et al. [70]. FM showed an increased aversiveness to non-painful stimuli such as loud noise. Also, Crombez et al. [71] reported significant correlations between hypervigilance and pain intensity in FM patients. Furthermore, exposure to stressful situations, including noise, lights, and weather, is known to exacerbate symptoms of FM, including pain [72].

In addition, FM patients with catastrophic thoughts report increased pain intensities [73-75]. Hassett et al. [74] found catastrophizing (27\% of the variance) and depression $(30 \%$ of the variance) to be significant predictors of pain. Finally, kinesiophobia and fear of pain are related to pain severity in patients with FM [76].

The foregoing relations between emotions or cognitions and reported pain severity support the hypothesis of cognitive emotional sensitization in FM.
Central abnormalities in FM FM patients differ from healthy persons in regional cerebral blood flow ( $\mathrm{rCBF}$ ) distribution in several brain structures involved in pain processing and pain modulation both at rest and during experimental pain induction. Patients with FM exhibited significantly lower rCBF levels, during rest, in the thalamus and the caudate nucleus [17]. Dysregulation of thalamic activity and hypoperfusion of the caudate nucleus may contribute to the abnormal pain modulation, given the results of previous investigations [77-79]. In addition to nociceptive transmission, the thalamus also plays an important role in pain modulation. Animal studies proved that thalamic stimulation induces analgesia and lesions of the thalamus cause hyperalgesia [77, 78].

Similarly, stimulating the caudate nucleus decreases pain behavior [79]. During pain induction in patients with FM, the absence of significant thalamic activation and a bilateral activation of the somatosensory cortices and the right anterior cingulated cortex was seen [80]. The patterns of cortical activation may be characteristic of patients with allodynia, and pain-induced activation of the right anterior cingulated cortex is associated with the use of maladaptive coping strategies [81]. Patients recruited by Bradley et al. [80] indeed reported significantly greater use of emotionfocused coping strategies (e.g., praying and hoping) during pressure stimulation. In addition, increased right frontal brain activity seemed related to increased pain sensitivity [82].

Furthermore, FM patients are characterized by relatively high cerebrospinal fluid levels of substance P [20]. This finding indicates that abnormal brain activity in persons with FM is associated with abnormal CSF levels of a neuropeptide involved in pain transmission [80]. In addition, it is shown that a subgroup of FM patients present with mycoplasma infections [83]. Infection triggers the release of the pro-inflammatory cytokine interleukin- $1 \beta$, which is known to play a major role in inducing cyclooxygenase-2 (COX-2) and prostaglandin E2 expression in the central nervous system [84].

Peripheral nerve terminals can be sensitized by elevated COX-2 amounts and prostaglandin E2. Peripheral infections are even able to activate spinal cord glia, leading to the release of NO and proinflammatory cytokines, enhancing the pain response [85]. Physiological symptoms, such as pain, can be explained by these mechanisms ("sickness response").

\section{Central sensitization in CFS?}

Direct evidence supporting the central sensitization hypothesis in CFS patients is currently lacking. But the present knowledge concerning CFS is suggestive of a central process similar to that seen in FM, given the great overlap between the two diseases and the observed similarities. 
First, lower pain thresholds at different sites (hyperalgesia) are reported in patients with CFS, compared to controls [86, 87]. Similar to FM, the lack of peripheral tissue damage and the lack of a distinct localization of the pain complaints are suggestive of a central abnormality responsible for the chronic widespread pain. To our knowledge, there are no investigations that focused on abnormal wind-up, temporal summation, or spatial summation in CFS, to collect evidence for central sensitization in CFS. Yet, evidence of a dysfunctional central anti-nociceptive mechanism in CFS has been proved by Whiteside et al. [88]. They reported a decrease of pain threshold in patients with CFS after graded exercise, while healthy controls present an increased pain threshold. These findings are similar to those of Vierck et al. [68] in FM patients.

Secondly, the frequently reported opportunistic infections [89, 90] may lead to the "sickness response" and complies with the central sensitization hypothesis, as explained above. Indeed, elevated NO levels have been documented in CFS patients [91]. As earlier mentioned, NO plays an important role in the history of central sensitization and, therefore, central sensitization caused by NO would be likely in patients with CFS. The release of excessive amounts of Substance P in the CSF, however, could not be documented in patients with CFS, in contrast to FM patients [21]. The CFS patients in this study, however, did not experience chronic widespread pain, and it is not clear if they fulfilled the 1994 CDC criteria [2]. Given that $70 \%$ of the CFS patients do fulfill the ACR criteria for widespread pain [12], it is striking that the patients included in the investigation of Evengard et al. [21] (focused on the source of pain) did not report these pain complaints. Further research on that matter should analyze the CSF of CFS patients (fulfilling the Fukuda criteria) suffering from chronic widespread pain.

A third important argument in the central sensitization theory for CFS concerns the cognitive, psychological, and behavioral changes in patients diagnosed with CFS. CFS patients often present with depression [6, 92], catastrophizing [93, 94], somatization [95, 96], and kinesiophobia or fear avoidance [97-99]. In CFS, it is known that these psychosocial aspects are important factors in maintaining the complaints of CFS. These cognitions and emotions are able to influence pain perception via modulation of the descending pathways [44]. Furthermore, these "cognitive styles" and "personality traits" have earlier been mentioned to be associated with the amplification and the extension of pain [49-52].

Finally, brain imaging already provided evidence for altered brain activity in CFS. Patterns of functional brain activity in patients with FM are quite different from those in patients with CFS. Patients with CFS, relative to controls, showed significantly lower blood perfusion in the brain stem
[17, 18]. Patients with FM exhibited significantly lower rCBF levels, during rest, in the thalamus and the caudate nucleus [19]. However, the areas are different in FM and in CFS; both the affected areas could be related to central pain processing. Low brain stem $\mathrm{rCBF}$ levels may contribute to abnormal function of the locus ceruleus in patients with CFS. The locus ceruleus is involved in controlling descending anti-nociceptive pathways from the brain to the spinal dorsal horn [56]. In consequence, pain experiences of patients with CFS may be related to low resting state levels of functional activity in the brain stem [80].

\section{Conclusion}

Chronic widespread pain can be the consequence of central sensitization. Central sensitization is known as an increased central neuronal responsiveness and causes hyperalgesia, allodynia, and referred pain and hyperalgesia across multiple spinal segments, leading to chronic widespread pain. Possible triggers for sensitization of the spinal cord have extensively been discussed, such as wind-up or temporal summation, dysregulated descending inhibitory pathways, and upregulated facilitatory modulation. Windup or temporal summation is the result of repetitive noxious stimuli, leading to an increase in electrical discharges in the dorsal horn. Inhibitory modulation can be impaired by abnormalities in the central nervous system and the facilitatory pain pathways can be stimulated by certain behavioral and cognitive factors.

This theoretical background can be applied to FM. In FM, studies already provided evidence for central sensitization as the cause of chronic pain. Temporal summation was found to be more facilitated, and the inhibitory pain modulation seemed impaired in FM patients. These findings can explain the chronic spontaneous pain in FM. Furthermore, some central abnormalities could be examined/objectified in FM: 1) hyperexcitability of the spinal cord, 2) decreased perfusion of pain-related brain structures, and 3) high levels of substance P in CSF. In addition, FM patients often present with pain hypervigilance, maladaptive coping strategies, and catastrophic thoughts, leading to cognitive central sensitization.

Based on the knowledge on central sensitization, on FM and on CFS, it is suggested that chronic widespread pain in CFS is the consequence of central sensitization. There are arguments and probable mechanisms that could explain this phenomenon in CFS. Also, in other chronic pain populations, central sensitization may play a key role. In fact, there are many similarities between CFS patients and other chronic pain populations such as patients with chronic lowback pain, whiplash, FM, etc. The psychosocial factors, for example, have been proved to contribute to pain perception 
in these different pain populations. But the specific nature of CFS such as the immunological abnormalities, elevated NO amounts, preceding infections etc., invites further research, in particular, on the possible contributory role of these abnormalities to pain processing in CFS.

In FM, many researches have been conducted to prove the theory of central sensitization. In CFS, however, it sticks to "supposing." To give a scientific basis to the theory, the protocols applied in FM investigations could be used for patients with CFS. It would, for example, be interesting to test the efficacy of temporal summation in CFS. The inhibitory control of pain could be another point of interest. The influence of exercise on pain tolerance has already been studied in CFS [88], however, on a relatively small sample. On the contrary, spatial summation has, to our knowledge, never been investigated in CFS. Furthermore, the role of depression, hypervigilance, kinesiophobia, catastrophising, etc. on chronic pain in CFS requires further research. To obtain more direct and objective information on central sensitization, the protocol described by Banic et al. [57] could be used to test the sensitivity of the central nervous system. Clearly, there are many possible research areas to test the hypothesis, but there is still a long way to go to elucidate the nature of the chronic pain in CFS.

\section{References}

1. Holmes GP, Kaplan JE, Gantz NM, Komaroff AL, Schonberger LB, Strauss SE, Jones JF, Dubois, Cunningham-Rundles C, Pawha S, Tosato G, Zegans LS, Purtilo DT, Brown N, Schooley RT, Brus I (1988) Chronic fatigue syndrome: a working case definition. Ann Intern Med 108:387-389

2. Fukuda K, Strauss SE, Hickie I, Sharpe MC, Dobbins JG, Komaroff AL; The International Chronic Fatigue Syndrome Study Group (1994). The chronic fatigue syndrome, a comprehensive approach to its definition and study. Ann Intern Med 121:953-959

3. Buchwald D (1996) Fibromyalgia and chronic fatigue syndrome: similarities and differences. Rheum Dis Clin North Am 22:219-243

4. Goldenberg DL, Simms RW, Geiger A, Komaroff AL (1990) High frequency of fibromyalgia in patients with chronic fatigue seen in primary care practice. Athritis Rheum 33:387-391

5. Goldenberg DL (1991) Fibromyalgia, chronic fatigue syndrome, and myofascial pain syndrome. Curr Opin Rheumatol 3:247-258

6. Jason LA, Richman JA, Rademaker AW, Jordan KM, Plioplys AV, Taylor RR, McCready W, Huang CF, Plioplys S (1999) A community-based study of chronic fatigue syndrome. Arch Intern Med 159:2129-2137

7. Nishikai M, Tomomatsu S, Hankins RW, Takagi S, Miyachi K, Kosaka S, Akiya K (2001) Autoantibodies to a 68/48 kDa protein in chronic fatigue syndrome and primary FM: a possible marker for hypersomnia and cognitive disorders. Rheumatology 40:806-810

8. Nijs J, De Meirleir K, Truyen S (2004) Hypermobility in patients with chronic fatigue syndrome: preliminary observations. J Musculoskelet Pain 12:9-17

9. Tan EM, Sugura K, Gupta S (2002) The case definition of chronic fatigue syndrome. J Clin Immunol 22:8-12

10. Nijs J, Vaes P, McGregor N, Van Hoof E, De Meirleir K (2003) Psychometric properties of the Dutch Chronic Fatigue Syndrome-
Activities and Participation Questionnaire (CFS-APQ). Phys Ther 83:444-454

11. Meeus M, Nijs J, De Meirleir K (2006) Chronic musculoskeletal pain in patients with chronic fatigue syndrome: a systematic review. Eur J Pain (in press)

12. Wolfe F, Smythe HA, Yunus MB, Bennett RM, Bombardier C, Goldenberg DL, Tugwell P, Campbell SM, Abeles M, Clark P, Fam AG, Farber SJ, Fiechtner JJ, Franklin CM, Gatter RA, Hamaty D, Lessard J, Lichtbroun AS, Masi AT, McCain GA, Reynolds WJ, Romano TJ, Russel IJ, Sheon RP (1990) The American College of Rheumatology 1990 criteria for the classification of fibromyalgia. Arthritis Rheum 33:160-172

13. Komaroff AL, Fagioli LR, Geiger AM, Doolittle TH, Lee J, Kornish RJ, Gleit MA, Guerriero RT (1996) An examination of the working case definition of chronic fatigue syndrome. Am J Med 100:56-64

14. Nijs J, Van de Velde B, De Meirleir K (2005) Pain in patients with chronic fatigue syndrome: does nitric oxide trigger central sensitization? Med Hypotheses 64:558-562

15. Bradley LA, McKendree-Smith, Alarcon GS (2000) Pain complaints in patients with fibromyalgia versus chronic fatigue syndrome. Curr Rev Pain 4:148-157

16. Nijs J, De Meirleir K (2005) Impairments of the 2-5A synthetase/ RNase L pathway in chronic fatigue syndrome. In Vivo 9:1013-1022

17. Costa DC, Tannock C, Brostoff J (1995) Brainstem perfusion is impaired in chronic fatigue syndrome. QJM 88:767-773

18. Tirelli U, Chierichetti F, Tavio M, Simonelli C, Bianchin G, Zanco P, Ferlin G (1998) Brain positron emission tomography (PET) in chronic fatigue syndrome: preliminary data. Am J Med 105:54S-58S

19. Mountz JM, Bradley LA, Modell JG, Alexander RW, TrianaAlexander M, Aaron LA, Stewart KE, Alarcon GS, Mountz JD (1995) Fibromyalgia in women. Abnormalities of regional cerebral blood flow in the thalamus and the caudate nucleus are associated with low pain threshold levels. Arthritis Rheum 38:926-938

20. Russell IJ, Orr MD, Littman B, Vipraio GA, Alboukrek D, Michalek JE, Lopez Y, MacKillip F (1994) Elevated cerebrospinal fluid levels of substance $\mathrm{P}$ in patients with the fibromyalgia syndrome. Arthritis Rheum 37:1593-1601

21. Evengard B, Nilsson CG, Lindh G, Lindquist L, Eneroth P, Fredrikson S, Terenius L, Henriksson KG (1998) Chronic fatigue syndrome differs from fibromyalgia. No evidence for elevated substance P levels in cerebrospinal fluid of patients with chronic fatigue syndrome. Pain 78:153-155

22. Winkelstein BA (2004) Mechanisms of central sensitization, neuroimmunology and injury biomechanics in persistent pain: implications for musculoskeletal disorders. J Electromyogr Kinesiol 14:87-93

23. Merskey H, Bogduk N (1994) Classification of chronic pain. Descriptions of chronic pain syndromes and definitions of pain terms, 2nd edn. IASP, Seattle

24. Staud R (2002) Evidence of involvement of central neural mechanisms in generating FM pain. Curr Rheumatol Rep 4:299-305

25. Staud R, Smitherman ML (2002) Peripheral and central sensitization in FM: pathogenic role. Curr Pain Headache Rep 6:259-266

26. Eriksen HR, Ursin H (2004) Subjective health complaints, sensitization, and sustained cognitive activation (stress). J Psychosom Res 56:445-448

27. Baranauskas G, Nistri A (1998) Sensitization of pain pathways in the spinal cord: cellular mechanisms. Prog Neurobiol 54:349-365

28. DeLeo JA, Winkelstein BA (2002) Physiology of chronic spinal pain syndromes: from animal models to biomechanics. Spine 27:2526-2537

29. Wall P, Melzack R (1994) Textbook of pain, 3rd edn. ChurchillLivingstone, London

30. Li J, Simone DA, Larson AA (1999) Windup leads to characteristics of central sensitization. Pain 79:75-82 
31. Coderre TJ, Katz J, Vaccarino AL, Melzack R (1993) Contribution of central neuroplasticity to pathological pain: review of clinical and experimental evidence. Pain 52:259-285

32. Graven-Nielsen T, Arendt-Nielsen L (2002) Peripheral and central sensitization in musculoskeletal pain disorders: an experimental approach. Curr Rheumatol Rep 4:313-321

33. Kidd BL, Urban LA (2001) Mechanisms of inflammatory pain. Br J Anaesth 87:3-11

34. Gracely RH, Grant MA, Giesecke T (2003) Evoked pain measures in fibromyalgia. Best Pract Res Clin Rheumatol 17:593-609

35. Mendell LM, Wall PD (1965) Responses of single dorsal cord cells to peripheral cutaneous unmyelinated fibres. Nature 206:9799

36. Bennett GJ (2000) Update on the neurophysiology of pain transmission and modulation: focus on the NMDA-receptor. J Pain Symptom Manage 19:S2-S6

37. Meller ST, Gebhart GF (1993) Nitric oxide (NO) and nociceptive processing in the spinal cord. Pain 52:127-136

38. Luo ZD, Cizkova D (2000) The role of nitric oxide in nociception. Curr Rev Pain 4:459-466

39. Liu H, Brown JL, Jasmin L, Maggio JE, Vigna SR, Mantyh PW, Basbaum AI (1994) Synaptic relationship between substance P and the substance P receptor: light and electron microscopic characterization of the mismatch between neuropeptides and their receptors. Proc Natl Acad Sci U S A 91:1009-1013

40. Price DD, Hu JW, Dubner R, Gracely RH (1977) Peripheral suppression of first pain and central summation of second pain evoked by noxious heat pulses. Pain 3:57-68

41. Dubner R, Ren K (1999) Endogenous mechanisms of sensory modulation. Pain Suppl 6:S45-S53

42. Wei F, Dubner R, Ren K (1999) Dorsolateral funiculus-lesions unmask inhibitory or disfacilitatory mechanisms which modulate the effects of innocuous mechanical stimulation on spinal Fos expression after inflammation. Brain Res 820:112-116

43. Ren K, Dubner R (1996) Enhanced descending modulation of nociception in rats with persistent hindpaw inflammation. J Neurophysiol 76:3025-3037

44. Zusman M (2002) Forebrain-mediated sensitization of central pain pathways: 'non-specific' pain and a new image for MT. Man Ther 7:80-88

45. Woolf CJ, Salter MW (2000) Neuronal plasticity: increasing the gain in pain. Science 288:1765-1769

46. Le Bars D, Villanueva L (1988) Electrophysiological evidence for the activation of descending inhibitory controls by nociceptive afferent pathways. Prog Brain Res 77:275-299

47. Rygh LJ, Tjolsen A, Hole K, Svendsen F (2002) Cellular memory in spinal nociceptive circuitry. Scand J Psychol 43:153-159

48. Brosschot JF (2002) Cognitive-emotional sensitization and somatic health complaints. Scand J Psychol 43:113-121

49. Waddell G, Newton M, Henderson I, Somerville D, Main CJ (1993) A Fear-Avoidance Beliefs Questionnaire (FABQ) and the role of fear-avoidance beliefs in chronic low back pain and disability. Pain 52:157-168

50. Vlaeyen JW, Crombez G (1999) Fear of movement/(re)injury, avoidance and pain disability in chronic low back pain patients. Man Ther 4:187-195

51. Vlaeyen JW, Linton SJ (2000) Fear-avoidance and its consequences in chronic musculoskeletal pain: a state of the art. Pain 85:317-332

52. Turner JA, Jensen MP, Romano JM (2000) Do beliefs, coping, and catastrophizing independently predict functioning in patients with chronic pain? Pain 85:115-125

53. Treede RD, Meyer RA, Raja SN, Campbell JN (1992) Peripheral and central mechanisms of cutaneous hyperalgesia. Prog Neurobiol 38:397-421

54. Simms RW, Roy SH, Hrovat M, Anderson JJ, Skrinar G, LePoole SR, Zerbini CA, de Luca C, Jolesz F (1994) Lack of association between fibromyalgia syndrome and abnormalities in muscle energy metabolism. Arthritis Rheum 37:794-800

55. Staud R, Vierck CJ, Cannon RL, Mauderli AP, Price DD (2001) Abnormal sensitization and temporal summation of second pain (wind-up) in patients with fibromyalgia syndrome. Pain 91:165-175

56. Clauw DJ, Chrousos GP (1997) Chronic pain and fatigue syndromes: overlapping clinical and neuroendocrine features and potential pathogenic mechanisms. Neuroimmunomodulation 4:134-153

57. Banic B, Petersen-Felix S, Andersen OK, Radanov BP, Villiger PM, Arendt-Nielsen L, Curatolo M (2004) Evidence for spinal cord hypersensitivity in chronic pain after whiplash injury and in fibromyalgia. Pain 107:7-15

58. Koelbaek Johansen M, Graven-Nielsen T, Schou Olesen A, Arendt-Nielsen L (1999) Generalised muscular hyperalgesia in chronic whiplash syndrome. Pain 83:229-234

59. Price DD, Staud R, Robinson ME, Mauderli AP, Cannon R, Vierck CJ (2002) Enhanced temporal summation of second pain and its central modulation in fibromyalgia patients. Pain 99:49-59

60. Sorensen J, Graven-Nielsen T, Henriksson KG, Bengtsson M, Arendt-Nielsen L (1998) Hyperexcitability in fibromyalgia. J Rheumatol 25:152-155

61. Julien N, Goffaux P, Arsenault P, Marchand S(2005) Widespread pain in fibromyalgia is related to a deficit of endogenous pain inhibition. Pain 114:295-302

62. Curatolo M, Petersen-Felix S, Arendt-Nielsen L, Giani C, Zbinden AM, Radanov BP (2001) Central hypersensitivity in chronic pain after whiplash injury. Clin J Pain 17:306-315

63. Sterling M, Jull G, Vicenzino B, Kenardy J (2003) Sensory hypersensitivity occurs soon after whiplash injury and is associated with poor recovery. Pain 104:509-517

64. Arendt-Nielsen L, Graven-Nielsen T (2003) Central sensitization in fibromyalgia and other musculoskeletal disorders. Curr Pain Headache Rep 7:355-361

65. Lautenbacher S, Rollman GB (1997) Possible deficiencies of pain modulation in fibromyalgia. Clin J Pain 13:189-196

66. Kosek E, Hansson P (1997) Modulatory influence on somatosensory perception from vibration and heterotopic noxious conditioning stimulation (HNCS) in fibromyalgia patients and healthy subjects. Pain 70:41-51

67. Lautenbacher S, Rollman GB, McCain (1997) Multi-method assessment of experimental and clinical pain in patients with fibromyalgia. Pain 59:45-53

68. Vierck CJ Jr, Staud R, Price DD, Cannon RL, Mauderli AP, Martin AD (2001) The effect of maximal exercise on temporal summation of second pain (windup) in patients with fibromyalgia syndrome. J Pain 2:334-344

69. Staud R, Robinson ME, Price DD (2005) Isometric exercise has opposite effects on central pain mechanisms in fibromyalgia patients compared to normal controls. Pain 118:176-184

70. McDermid AJ, Rollman GB, McCain GA (1996) Generalized hypervigilance in fibromyalgia: evidence of perceptual amplification. Pain 66:133-144

71. Crombez G, Baeyens F, Eelen P (1994) Sensory and temporal information about impending pain: the influence of predictability on pain. Behav Res Ther 32:611-622

72. Waylonis GW, Heck W (1992) Fibromyalgia syndrome. New associations. Am J Phys Med Rehabil 71:343-348

73. Martin MY, Bradley LA, Alexander RW, Alarcon GS, TrianaAlexander M, Aaron LA, Alberts KR (1996) Coping strategies predict disability in patients with primary fibromyalgia. Pain 68:45-53

74. Hassett A, Cone JD, Patella SJ, Sigal LH (2000) The role of catastrophizing in the pain and depression of women with fibromyalgia syndrome. Arthritis Rheum 11:2493-2500

75. Geisser ME, Casey KL, Brucksch CB, Ribbens CM, Appleton BB, Crofford LJ (2003) Perception of noxious and innocuous heat 
stimulation among healthy women and women with fibromyalgia: association with mood, somatic focus, and catastrophizing. Pain 102:243-250

76. Turk DC, Robinson JP, Burwinkle T (2004) Prevalence of fear of pain and activity in patients with fibromyalgia syndrome. J Pain $5: 483-490$

77. Willis WD Jr (1997) Nociceptive functions of thalamic neurons. In: Steriade M, Jones EG, McCormick DA (eds) Thalamus: experimental and clinical aspects. Elsevier Science, Oxford, p 373-424

78. Saade NE, Kafrouni AI, Saab CY, Atweh SF, Jabbur SJ (1999) Chronic thalamotomy increases pain-related behavior in rats. Pain 83:401-409

79. Chudler EH, Sugiyama K, Dong WK (1993) Nociceptive responses in the neostriatum and globus pallidus of the anesthetized rat. J Neurophysiol 69:1890-1903

80. Bradley LA, McKendree-Smith, Alberts KR, Alarcon GS, Mountz JM, Deutsch G (2000) Use of neuroimaging to understand abnormal pain sensitivity in fibromyalgia. Curr Rheum Rep 2:141-148

81. Jones AK, Derbyshire SW (1997) Reduced cortical responses to noxious heat in patients with rheumatoid arthritis. Ann Rheum Dis 56:601-607

82. Hsieh JC, Belfrage M, Stone-Elander S, Hansson P, Ingvar M (1995) Central representation of chronic ongoing neuropathic pain studied by positron emission tomography. Pain 63:225-236

83. Nasralla M, Haier J, Nicolson GL (1999) Multiple mycoplasmal infections detected in blood of patients with chronic fatigue syndrome and/or fibromyalgia syndrome. Eur J Clin Microbiol Infect Dis 18:859-865

84. Samad TA, Moore KA, Sapirstein A, Billet S, Allchorne A, Poole S, Bonventre JV, Woolf CJ (2001) Interleukin-1 beta-mediated induction of COX-2 in the CNS contributes to inflammatory pain hypersensitivity. Nature 410:471-475

85. Watkins LR, Maier SF (1999) Implications of immune-to-brain communication for sickness and pain. Proc Natl Acad Sci U S A 96:7710-7713

86. Vecchiet J, Cipollone F, Falasca K, Mezzetti A, Pizzigallo E, Bucciarelli T, De Laurentis S, Affaitati G, De Cesare D, Giamberardino MA (2003) Relationship between musculoskeletal symptoms and blood markers of oxidative stress in patients with chronic fatigue syndrome. Neurosci Lett 335:151-154

87. Vecchiet L, Montanari G, Pizzigallo E, Iezzi S, de Bigontina P, Dragani L, Vecchiet J, Giamberardino MA (1996) Sensory characterization of somatic parietal tissues in humans with chronic fatigue syndrome. Neurosci Lett 208:117-120

88. Whiteside A, Hansen S, Chaudhuri A (2004) Exercise lowers pain threshold in chronic fatigue syndrome. Pain 109:497-499

89. Vojdani A, Choppa PC, Tagle C, Andrin R, Samini B, Lapp CW (1998) Detection of Mycoplasma genus and Mycoplasma fermentans by PCR in patients with chronic fatigue syndrome. FEMS Immunol Med Microbiol 22:355-365

90. Nijs J, Nicolson GL, De Becker P, Coomans D, De Meirleir K (2002) High prevalence of Mycoplasma infections among European chronic fatigue syndrome patients. Examination of four Mycoplasma species in blood of chronic fatigue syndrome patients. FEMS Immunol Med Microbiol 34:209-214

91. Kurup RK, Kurup PA (2003) Hypothalamic digoxin, cerebral chemical dominance and myalgic encephalomyelitis. Int J Neurosci 113:683-701

92. Morriss RK, Ahmed M, Wearden AJ, Mullis R, Strickland P, Appleby L, Campbell IT, Pearson D (1999) The role of depression in pain, psychophysiological syndromes and medically unexplained symptoms associated with chronic fatigue syndrome. J Affect Disord 55:143-148

93. Petrie K, Moss-Morriss R, Weinman J (1995) The impact of catastrophic beliefs on functioning in chronic fatigue syndrome. J Psychosom Res 39:31-37

94. Sharpe M (1998) Cognitive behavior therapy for chronic fatigue syndrome: efficacy and implications. Am J Med 105:104S-109S

95. Fischler B, Dendale P, Michiels V, Cluydts R, Kaufman L, De Meirleir K (1997) Physical fatigability and exercise capacity in chronic fatigue syndrome: associations with disability, somatization and psychopathology. J Psychosom Res 42:369-378

96. Johnson SK, Deluca J, Natelson BH (1996) Assessing somatization disorder in the chronic fatigue syndrome. Psychosom Med 58:50-57

97. Silver A, Haeney M, Vijayadurai P, Wilks D, Pattrick M, Main CJ (2002) The role of fear of physical movement and activity in chronic fatigue syndrome. J Psychosom Res 52:485-493

98. Nijs J, De Meirleir K, Duquet W (2004) Kinesiophobia in chronic fatigue syndrome: assessment and associations with disability. Arch Phys Med Rehabil 85:1586-1592

99. Nijs J, Vanherberghen K, Duquet W, De Meirleir K (2004) Chronic fatigue syndrome: lack of association between painrelated fear of movement and exercise capacity and disability. Phys Ther 84:696-705 